\title{
The shock response of a rendered porcine fat
}

\author{
J. M. Wilgeroth, ${ }^{\text {a) }}$ P. J. Hazell, and G. J. Appleby-Thomas \\ Cranfield Defence and Security, Cranfield University, Shrivenham, Swindon SN6 8LA, United Kingdom
}

(Received 26 July 2010; accepted 8 September 2010; published online 15 November 2010)

\begin{abstract}
Characterization of the shock response of biological materials is required in order to develop an understanding of how such materials behave under high strain-rate loading. In this work, a predominately linear $\mathrm{U}_{\mathrm{s}}-\mathrm{u}_{\mathrm{p}}$ Hugoniot relationship for a rendered porcine fat has been established using the plate-impact technique. This has been shown to take the form $\mathrm{U}_{\mathrm{s}}=1.58+2.47 \mathrm{u}_{\mathrm{p}}\left(\rho_{0}\right.$ $=0.945 \mathrm{~g} / \mathrm{cc}$ ) and comparison has been made between the dynamic behavior of the adipose material and both $20 \mathrm{wt} \%$ ballistic gelatin and water. The adipose material has been shown to behave in likeness with simple polymers such as polyethylene and to strengthen under shock loading, unlike ballistic gelatin, which has been shown to behave hydrodynamically. An experimental design incorporating direct insertion of lateral stress gauges within the rendered fat has given insight into both the behavior of lateral gauges and the lateral stress response of the material under dynamic loading. () 2010 American Institute of Physics. [doi:10.1063/1.3501046]
\end{abstract}

\section{INTRODUCTION}

In order to provide the required ballistic protection to an individual, damage mechanisms, and the response of the body and its tissues to dynamic loading must be understood. Wounding occurs through the mechanisms of blast waves in air/water, penetration from projectiles and fragments, bluntforce impact, and rapid acceleration/deceleration effects on the organs and limbs. The strain-rates and pressures encountered under these scenarios necessitate a knowledge of the high strain-rate response of such materials; typically strainrates $>10^{4} / \mathrm{s}$ are of interest.

The consequence of impact on body tissues, many of which are anisotropic and vary in composition and distribution from person to person, is notably complex. For this reason, material impact tests are often simplified in order to elucidate understanding of the governing mechanics i.e., complex three-dimensional problems such as ballistic impact events are often simplified into one-dimensional (1D) loading of materials over a range of strain-rates. Further, it is often necessary to analyze body materials in isolation in order to depict an understanding of how the body, as a whole system, will respond to dynamic loading.

The early example of McElhaney ${ }^{1}$ looked at the response of muscle tissue to a piston accelerated into the material via an air gun system. His conclusions related the cellular structure of the bovine muscle to 'humped regions' witnessed in the stress-strain curve of the material at specific strain rates, suggesting that, as strain increases, it is the inhibition of fluid movement between cells and the interstitial spacing between them that eventually leads to cell rupture and the observed incongruities in the stress-strain response. This work focused on a singular muscle type; hence, it is not possible to conclude that the observed behavior is typical of other muscle groups and function-specific muscle types such as smooth and cardiac muscle.

Saraf et al. ${ }^{2}$ investigated the dynamic response of soft

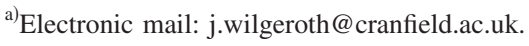

human tissues using the Kolsky bar technique to determine the uniaxial compression and shear response at various strain-rates. Soft tissues were interrogated at stresses below $25 \mathrm{MPa}$ and at strain-rates of 300-7700/s. The behavior of the materials under dynamic compression was represented by an approximately linear relationship between the pressure and the volumetric strain, while the relationship between the shear stress and the shear strain was found to be strongly non-linear. It was also shown from the shear response of the soft materials that minimal stress levels existed at low strainrates. However, a rapid stiffening and increase in stress occurred at higher stain-rates.

A similar approach, as used by Al-Mousawi et al. ${ }^{3}$ and Marais et al., ${ }^{4}$ has produced data on the compressive response of various biological materials such as porcine muscle, ${ }^{5}$ pig skin, ${ }^{6}$ and bovine muscle. ${ }^{7}$ In addition, analysis of the tissue simulant, ballistic gelatin, has also been carried out. $^{8}$ Such work has provided detailed insight into the response of biological and soft tissues at strain-rates up to approximately $10^{4} / \mathrm{s}$. However, despite such studies, there is a notable lack of data in the literature governing the response of such systems to shock, where the strain-rate would typically be $10^{5}-10^{6} / \mathrm{s}$.

While widely employed as a tissue stimulant, substantive research into the higher strain-rate or shock response of ballistic gelatin has only recently been investigated. Plateimpact experiments were employed by Shepherd et al. ${ }^{9}$ to determine equation-of-state data for $20 \mathrm{wt} \%$ ballistic gelatin for particle velocities $<1 \mathrm{~mm} / \mu \mathrm{s}$. Similar $\mathrm{U}_{\mathrm{s}}-\mathrm{u}_{\mathrm{p}}$ and $\mathrm{P}-\mathrm{u}_{\mathrm{p}}$ Hugoniot relationships to water ${ }^{10,11}$ were found and, in particular, gelatin was shown to behave hydrodynamically i.e., to possess negligible strength under shock loading. Further, ballistic gelatin was found to be unable to support a shear wave. Similar work on the shock compression of several bio-related materials was presented by Nagayama et al. ${ }^{10,11}$ Hugoniot relationships in the $\mathrm{U}_{\mathrm{s}}-\mathrm{u}_{\mathrm{p}}$ plane were established for water, $10 \%$ gelatin solution, $20 \%$ gelatin solution (in good agreement with Shepherd et al. ${ }^{9}$ ), and both $10 \%$ and 


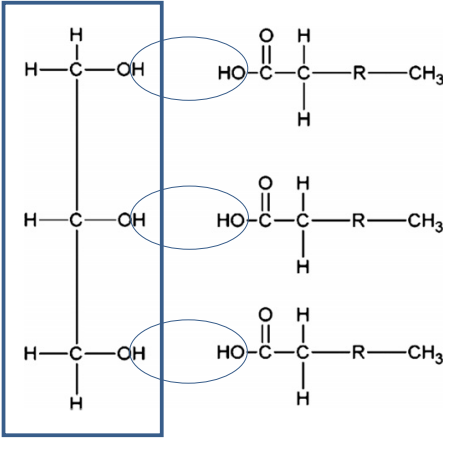

Glycerol

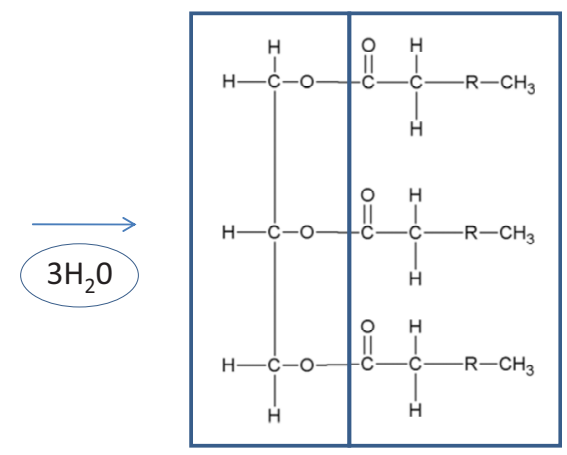

Triglyceride Molecule
FIG. 1. (Color online) Triglyceride formation [adapted from Mackenna and Callander (Ref. 13)].
$20 \%$ sodium chloride $(\mathrm{NaCl})$ solution. Plate-impact experiments were also employed to interrogate the shock response of chicken breast meat. Interestingly, the Hugoniot data for this material was observed to be almost coincident with that of $20 \mathrm{wt} \%$ gelatin in the $\mathrm{U}_{\mathrm{s}}-\mathrm{u}_{\mathrm{p}}$ plane.

Tissue damage (wounding) as a result of ballistic/highstrain-rate events is unlikely to be an entirely hydrodynamic process. Consequently, penetration behavior in such a "weak" material as $20 \mathrm{wt} \%$ gelatin is unlikely to be comparable with the ballistic response of "stronger" body tissues such as muscle, bone, fat, and connective tissues, which are yet to be characterized under such loading regimes. Further, body tissues such as muscle exhibit anisotropic properties and, as a consequence, cannot be expected to behave in a uniform manner (as opposed to intimately mixed/isotropic ballistic gelatin blocks). Thus, there is a clear requirement for ballistic simulants to be more representative of the human body.

An important element of tissue is the adipose or "fat" layer. The literature regarding the compressive response of lard/body fat is limited, and quantitative analysis of dynamic loading on the material is yet to be undertaken. However, Nishioka and $\operatorname{Irie}^{12}$ did demonstrate that, under low (strain) rates of compression, the firmness of porcine perirenal fat increases with the percentage of saturated fatty acids within the material.

Triglycerides or triaglycerols, are the most common form of fat in the body, accounting for approximately $95 \%$ of all body fat. ${ }^{13,14}$ These fats are composed of a structure which is essentially a biological polymer. Usefully, unlike fatty tissues, the behavior of polymers under dynamic/shock loading has been extensively studied. The dynamic response of three simple polymers was investigated by Millett and Bourne, ${ }^{15}$ who looked at the shock response of polyethylene, polypropylene, and polystyrene by means of plate-impact experiment. Their results showed an increase in resistance to compression under shock with the complexity of side chain attachment of the polymer (i.e., polyethylene to polystyrene). While Millett and Bourne ${ }^{15}$ investigated the dynamic response of polymers at pressures $<6 \mathrm{GPa}$, Carter et al. ${ }^{16}$ provide insight into the shock response of various polymeric materials at pressures of 20-30 GPa.

Little work on the response of body tissues or tissue simulants at pressures in the order of GPa is apparent within the literature. Such pressures are obtained through 1D explosively-driven-hammer and plate-impact experiments. Further, no significant work appears to have been undertaken directly comparing the response of biological simulants with body tissues of either animal or human origin. In this work, plate-impact experiments have been conducted to investigate the $1 \mathrm{D}$ high strain-rate response of a commercially available lard. The primary aim of this work is to elucidate understanding of how the adipose element of more accurate tissue simulants will respond under impact. As discussed, mammalian tissues are complex and anisotropic in nature. Consequently, an understanding of the high strain-rate response of isolated tissue components is required before the behavior of more complex biological systems and anatomical regions, such as the organs and thorax, respectively, are considered. Further, the equation-of-state data derived here aims to inform the future development of hydrocode models, potentially providing insight into wound morphology and the investigation of protection concepts. This work is part of a wider study on the dynamic behavior of biological materials.

\section{EXPERIMENTAL METHODS}

\section{A. Materials}

The adipose material adopted in this work was a commercially available lard manufactured in the U.K. by Matthews Foods plc and retailed by the Co-operative Food Group under the product name "Fresh Fields Lard." The material was chosen as a good approximation of human fat tissues and adipose layers, due to its high fat content (approximately $99.8 \%$ ), and the requirement that such materials/ simulants comply with ethical regulations for the testing of animal and human tissues.

Figure 1 highlights the chemical structure and mechanisms involved with triglyceride formation (approximately $95 \%$ body fat). As discussed, it has been shown elsewhere ${ }^{12}$ that the percentage saturation of the fatty acid component of fat is a factor governing the firmness of the material.

The adipose target material was stored at $4{ }^{\circ} \mathrm{C}$ up until the point of target preparation. The longitudinal sound speed of the material was measured ultrasonically at room temperature using a Panametrics 5077PR pulser-receiver in the pulse-receive configuration and a $1.0 \mathrm{MHz}$ Panametrics quartz transducer. This relatively low frequency was adopted 


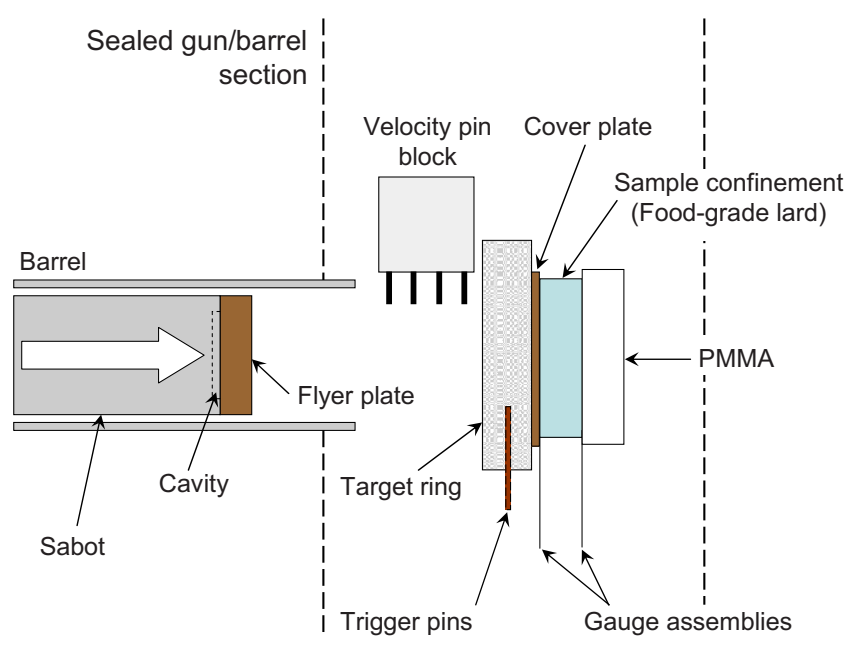

FIG. 2. (Color online) Experimental setup and target arrangement.

to ensure maximum penetration of the ultrasonic waves in the highly attenuating lard. A value of $c_{L}$ $=1.51 \pm 0.10 \mathrm{~mm} / \mu \mathrm{s}$ was determined. This is in good agreement with longitudinal wave speeds obtained elsewhere for gelatin ${ }^{9}$ and water $^{17} \quad(1.48 \pm 0.06 \mathrm{~mm} / \mu \mathrm{s}$ and $1.49 \mathrm{~mm} / \mu \mathrm{s}$, respectively). A shear wave speed for the material was not discernible, most likely due to the material's low stiffness. Target material density was measured using a Micromeritics AccuPyc 1330 Gas Pycnometer and was determined to be $0.945 \pm 0.006 \mathrm{~g} / \mathrm{cm}^{3}$ at room temperature.

\section{B. Measurement of longitudinal stress}

Food-grade lard was subjected to various shock pressures by means of plate-impact experiment ${ }^{18,19}$ using a $\varnothing 50 \mathrm{~mm}$ single-stage gas gun. ${ }^{20}$ The design specifications of the system ensure that all points of the projectiles' surface make contact with the target simultaneously upon impact, thus generating a planar (1D) shock within the material. This leads to all strain acting along the axis of impact such that:

$$
\varepsilon_{x} \neq \varepsilon_{y}=\varepsilon_{z}=0 \text { and } \sigma_{x} \neq \sigma_{y}=\sigma_{z} \neq 0 .
$$

Where subscript $x$ denotes the condition along the impact axis and subscripts $y$ and $z$ denote the conditions orthogonal to the impact axis.

A sequence of experiments were conducted to interrogate the longitudinal stresses generated within the sample material under shock-loading. Shock response of the target material was measured using Vishay Micro-Measurements \& SR-4 Manganin Pressure Gauges of type LM-SS-125CH-048 calibrated according to Rosenberg et $a .^{21}$ During impact, gauge response was monitored using Tektronix TDS 5104 Digital Phosphor Oscilloscopes (2GS/s). Subsequent analysis, employing the impedence matching technique, ${ }^{22}$ allowed for shock velocity-particle velocity $\left(\mathrm{U}_{\mathrm{s}}-\mathrm{u}_{\mathrm{p}}\right)$, pressure-particle velocity $\left(\mathrm{P}-\mathrm{u}_{\mathrm{p}}\right)$, and pressure-volume $(\mathrm{P}-\mathrm{v})$ Hugoniot relationships to be established for the sample material. A schematic highlighting key features of the experimental setup/ target assembly is shown in Fig. 2.

With the longitudinal targets, the adipose material was cast/encapsulated within a $\varnothing 60 \mathrm{~mm}$ aluminum ring (see Fig. $3)$. These were machined to a thickness of $10 \mathrm{~mm} \pm 20 \mu \mathrm{m}$,

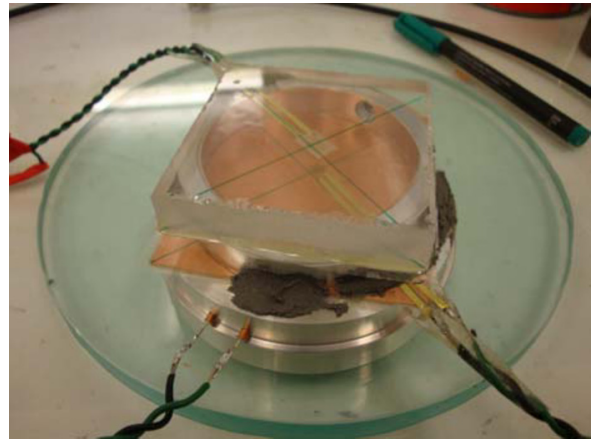

FIG. 3. (Color online) Precast lard target assembly.

with the mount faces of the ring finished flat and parallel to a tolerance of $10 \mu \mathrm{m}$. Before each experiment, sample thickness was carefully measured using a digital micrometer. When combined with knowledge of arrival times at the two sample-faces, this measurement allowed for calculation of shock velocity $\left(\mathrm{U}_{\mathrm{s}}\right)$ through the target material. In all cases, the sample material was encapsulated between a $1 \mathrm{~mm}$ copper cover plate and a polymethyl-methacrylate (PMMA) backing block (chosen due to its well-defined Hugoniot which allowed for subsequent calculation of stresses in the target material). The manganin gauges were insulated from both the sample material and the copper cover plate using a thin $(\sim 25 \mu \mathrm{m})$ Mylar $^{\circledR}$ layer.

An assembled plate-impact target for the measurement of longitudinal stresses within the adipose material is shown in Fig. 3. Liquid lard was cast at $50-60{ }^{\circ} \mathrm{C}$ into the aluminum sample-ring via a $\varnothing 7 \mathrm{~mm}$ hole machined into the side wall. While above the melting temperature of $35-40{ }^{\circ} \mathrm{C}$, this temperature is significantly below the temperatures and processing times employed in commercial rendering processes $\left(>100{ }^{\circ} \mathrm{C}\right.$ in steam processing and $1-5 \mathrm{~h}$, respectively). Thus, it seems reasonable to suggest that the casting process employed will have caused minimal or no significant alteration to the microstructure of the lard from that at the point of acquisition.

\section{Measurement of lateral stress}

A second set of experiments were conducted in order to investigate the lateral stresses generated within the adipose material under shock loading. The techniques employed to measure lateral stress are widely covered in the literature. ${ }^{23,24}$ However, the types of materials that are typically examined are metals and polymers, whose machinability allows for the placement of lateral stress gauges directly between prepared target-material halves. Aluminum rings of $\varnothing 60 \mathrm{~mm}$ and of 6 and $10 \mathrm{~mm}+/-20 \mu \mathrm{m}$ thickness with opposing faces machined flat and parallel to a tolerance of $10 \mu \mathrm{m}$ were employed for target-material confinement. Adhered to the front of the sample ring was a $1 \mathrm{~mm}$ thick copper cover-plate, while the rear of the target ring allowed for the insertion of the gauge-support assembly (see Fig. 4). The lateral response targets were initially assembled into a hollow-casing form prior to filling with liquid lard through one of two $4 \mathrm{~mm}$ holes machined into the side-wall of the target-rings; the second allowing for the release of air from the target void. The 

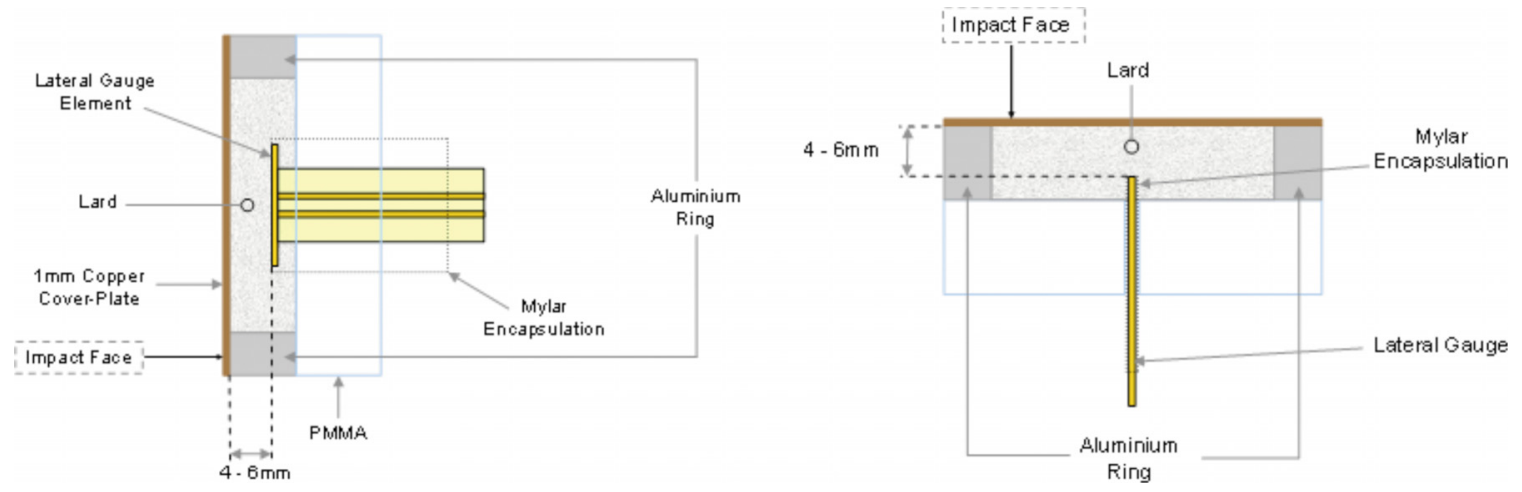

FIG. 4. (Color online) Side views of lateral gauge target assembly.

lateral gauges employed were of type J2M-SS-580SF-025 Vishay Micro-Measurements \& SR-4 Manganin Pressure Sensors, calibrated according to the method outline by Appleby-Thomas et al. ${ }^{25}$ (a technique is based upon the previous work of Rosenburg and Partom, ${ }^{26}$ Rosenburg and $\mathrm{Brar}^{27}$ and Millett et al. ${ }^{28}$ ). The lateral gauges were initially encapsulated between two $50 \mu \mathrm{m}$ Mylar ${ }^{\circledR}$ sheets prior to secondary confinement between two PMMA halves with flat mount faces. As shown in Fig. 4, this arrangement was then employed as the rear-surface of the hollow casing assembly, with the encased gauge protruding into the target cavity. Mylar ${ }^{\circledR}$ encapsulation was employed because it enhanced the stiffness of the pressure gauge. This property allowed for accurate alignment of the gauge element in relation to the impact axis at distances of 4 and $6 \mathrm{~mm}$ from the copper/lard impact boundary. In addition to experiments in which a Mylar $^{\circledR}$ encapsulating layer was used to surround the gauge element, experiments were also conducted in which the gauge element protruded further ahead of any encapsulation. In such configurations, only "as-cast" lard surrounded the gauge element. Distances of 4 and $6 \mathrm{~mm}$ from the front edge of the target material were, however, maintained. These two distinct types of lateral gauge experiments were undertaken in order to ascertain any effect of localized encapsulation on gauge response. All target components were bonded together with Pacer Technology Z-Poxy ${ }^{\mathrm{TM}}$, a two-part epoxy resin comprising an epoxy resin and mercaptan hardener.

\section{RESULTS AND DISCUSSION}

\section{A. Longitudinal response}

Shock response data of the adipose material for an impact velocity range of $39-882 \mathrm{~m} / \mathrm{s}$ is shown in Table I.

Figure 5 shows typical front/rear gauge responses for the dynamic loading of the adipose material. A number of key features common to most traces are apparent. These have been labeled (a)-(e). A small undershoot at shock arrival (a) occurred on the front surface gauge. This undershoot has been seen elsewhere ${ }^{29}$ and has been attributed to a capacitance effect as the conducting cover plate moves toward the insulated gauge. The two gauge traces are clearly resolved and possess a number of similar features, namely; (i) rapid rise times (b) of 100-123 ns (indicative of good target alignment), (ii) a constant (Hugoniot) stress behind the shock (c), and; (3) a distinctive separation of shock arrival times $(\Delta t)$.
Combined with knowledge of the sample thickness/ gauge separation, measurement of the interval between shock arrival at successive gauges $(\Delta \mathrm{t})$ allowed calculation of the shock velocity for a given experiment. In Fig. 5, the front gauge trace shows the stress-time behavior of the adipose material while the rear gauge response shows the stress observed in the PMMA backing. Given knowledge of the density and measured shock velocity in the target, it is possible to convert the rear gauge response to that in the target material using Eq. (1), where; $Z_{\text {Lard }}$ is the shock impedance of the lard, $\mathrm{Z}_{\mathrm{PMMA}}$ is the shock impedance of the PMMA, and in general, $\mathrm{Z}=\rho_{0} \mathrm{U}_{\mathrm{s}}$.

$$
\sigma_{\text {Lard }}=\frac{1}{2} \frac{\left(Z_{\text {Lard }}+Z_{\text {PMMA }}\right)}{Z_{\text {PMMA }}} \sigma_{\text {PMMA }} .
$$

Interestingly, the rear gauge response in Fig. 5 has a higher Hugoniot stress than the front gauge trace. From Eq. (1), this implies that the lard has a lower shock impedance than the PMMA. After evolution of the Hugoniot stress within the lard sample and PMMA backing, both materials show initially elastic release behavior (d). This is the result of release waves from the rear of the flyer catching up with the shock in the material. Finally, reloading of the adipose material occurs at (e).

In Fig. 6 the $\mathrm{U}_{\mathrm{s}}-\mathrm{u}_{\mathrm{p}}$ Hugoniot for the adipose sample material, based on the information presented in Table $\mathrm{I}$, is compared with the Hugoniot of 20 wt \% ballistic gelatin ${ }^{9}$ and water. ${ }^{10} \mathrm{U}_{\mathrm{s}}$ errors shown in the Hugoniot were calculated

TABLE I. Longitudinal experimental data.

\begin{tabular}{cccccc}
\hline \hline & $\begin{array}{c}\text { Flyer } \\
\text { thickness } \\
(\mathrm{mm})\end{array}$ & $\begin{array}{c}\text { Impact } \\
\text { velocity } \\
(\mathrm{m} / \mathrm{s})\end{array}$ & $\begin{array}{c}\mathrm{U}_{\mathrm{p}} \\
(\mathrm{mm} / \mu \mathrm{s})\end{array}$ & $\begin{array}{c}\mathrm{U}_{\mathrm{S}} \\
(\mathrm{mm} / \mu \mathrm{s})\end{array}$ & $\begin{array}{c}\sigma_{\mathrm{x}} \\
(\mathrm{GPa})\end{array}$ \\
\hline 1 & 10 & 39 & 0.04 & 1.44 & $\ldots$ \\
2 & 5 & 76 & 0.07 & 1.75 & 0.09 \\
3 & 5 & 79 & 0.08 & 1.82 & 0.12 \\
4 & 10 & 183 & 0.17 & 2.06 & 0.31 \\
5 & 10 & 310 & 0.29 & 2.29 & 0.67 \\
6 & 10 & 411 & 0.39 & 2.39 & 0.95 \\
7 & 5 & 489 & 0.46 & 2.77 & 1.26 \\
8 & 10 & 596 & 0.55 & 2.87 & 1.79 \\
9 & 10 & 758 & 0.70 & 3.26 & 2.63 \\
10 & 5 & 882 & 0.80 & 3.67 & 3.08 \\
\hline \hline
\end{tabular}




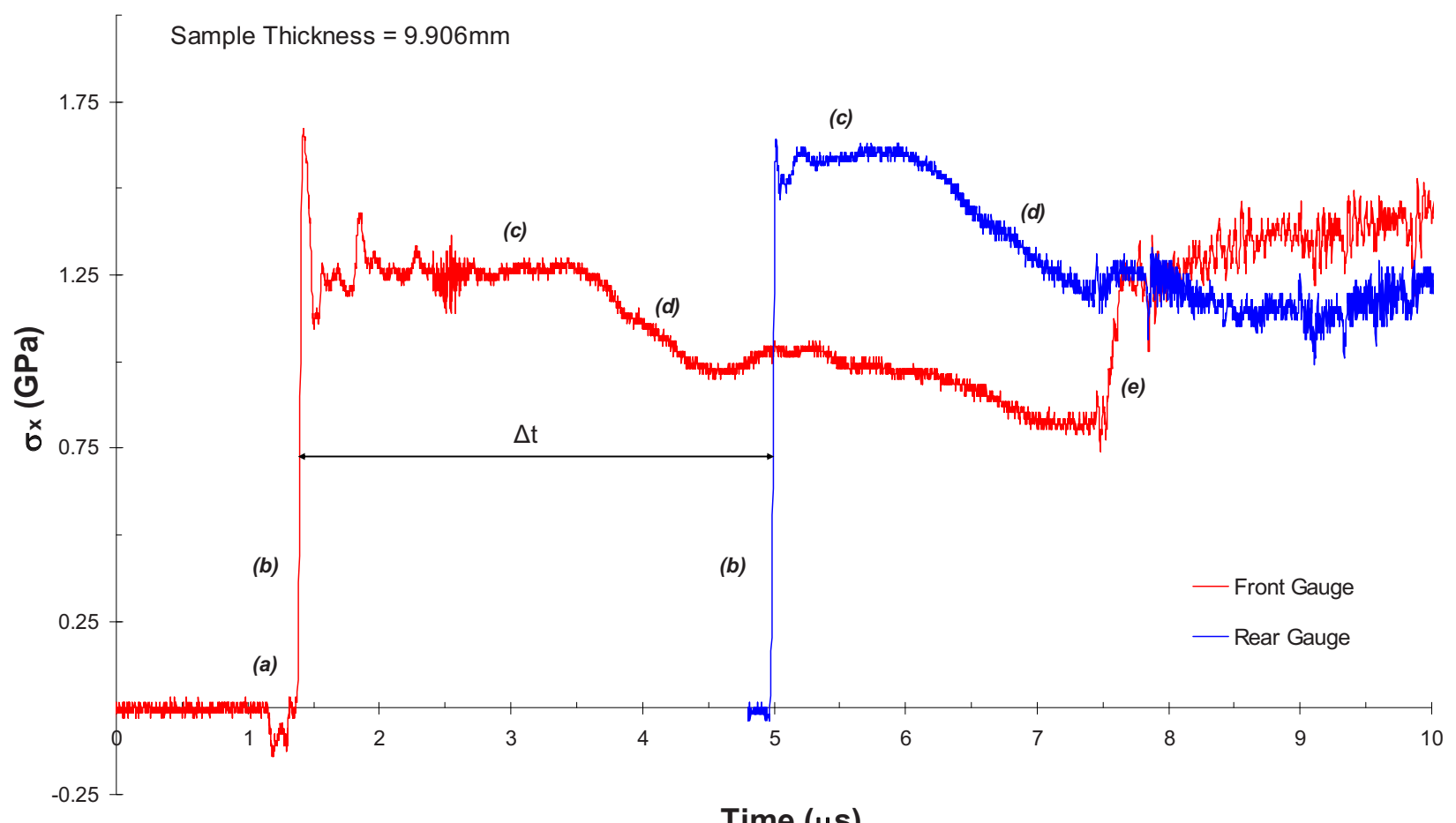

Time $(\mu \mathbf{s})$

FIG. 5. (Color online) $5 \mathrm{~mm} \mathrm{Cu}$ flyer impacting lard sample at $489 \mathrm{~m} / \mathrm{s}$.

from the possible range of shock arrival times $(\Delta t$ in Fig. 5) and are expressed as maximum and minimum values from the median shock arrival time.

The measured longitudinal sound speed of the adipose material $\left(c_{\mathrm{L}}=1.51 \pm 0.10 \mathrm{~mm} / \mu \mathrm{s}\right)$ holds good correlation with the corresponding values of $\mathrm{c}_{\mathrm{L}}$ and Hugoniot intercept for ballistic gelatin $(1.48 \pm 0.06 \mathrm{~mm} / \mu \mathrm{s}$ and $1.57 \mathrm{~mm} / \mu \mathrm{s}$, respectively $\left.{ }^{9}\right)$. Further, initial observations suggest that the Hugoniot relationships of water and ballistic gelatin (established elsewhere ${ }^{9,10}$ ) in the $\mathrm{U}_{\mathrm{s}}-\mathrm{u}_{\mathrm{p}}$ plane are somewhat similar to that of the rendered fat at particle velocities $<1 \mathrm{~mm} / \mu \mathrm{s}$.

Information within the literature suggests that the value of Poisson's ratio for fatty/adipose materials is approximately 0.5. Delalleau et al. ${ }^{30}$ determined the value of Poisson's ratio for subcutaneous fat as 0.48 from indentation studies while a value of 0.49 has been adopted during research into deep tissue injury. ${ }^{31}$ Further, a review presented by Palomar $e t a l .{ }^{32}$ highlighted the wider acceptance that a value for Poisson's ratio for fatty tissues is close to 0.5. As-

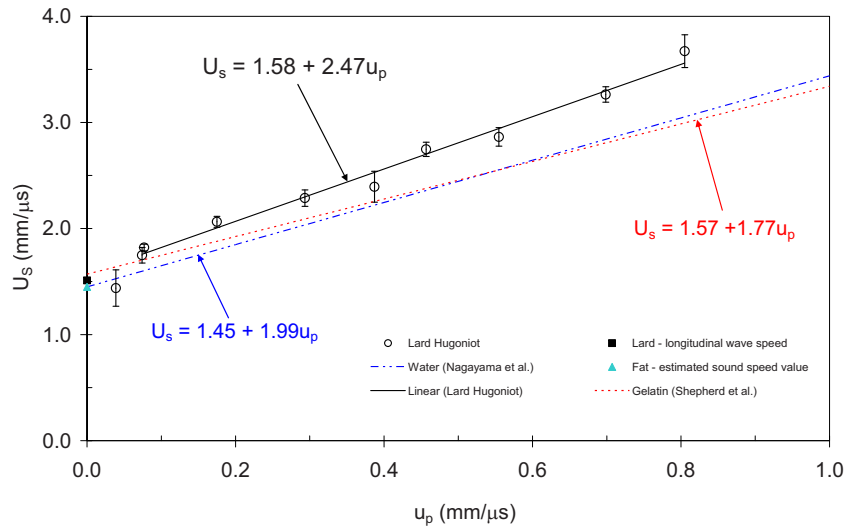

FIG. 6. (Color online) $\mathrm{U}_{\mathrm{s}}-\mathrm{u}_{\mathrm{p}}$ Hugoniot of the food-grade lard. sumption of a value of 0.47 for Poisson's ratio of the rendered porcine fat investigated in this work suggests a shear wave velocity of $0.35 \mathrm{~mm} / \mu \mathrm{s}$. This would equate to a bulk sound speed for the material of $1.45 \mathrm{~mm} / \mu \mathrm{s}$, in good agreement with values of 1.42 and $1.44 \mathrm{~mm} / \mu$ s established ultrasonically elsewhere. ${ }^{33,34}$ Increasing the value of Poisson's ratio for the adipose material to 0.49 (a value used elsewhere ${ }^{31}$ ) resulted in a calculated value of $c_{0}$ $=$ ca. $1.49 \mathrm{~mm} / \mu \mathrm{s}$. This value is significantly higher than the expected bulk sound speed for fat/fatty tissues taken from the literature $[1.42 \mathrm{~mm} / \mu \mathrm{s}$ (Ref. 33) and $1.44 \mathrm{~mm} / \mu \mathrm{s}$ (Ref. 34)]. Consequently, a value of $\nu=0.49$ was considered less suitable than the chosen value of 0.47. A value of $\mathrm{c}_{0}$ $=$ ca. $1.45 \mathrm{~mm} / \mu \mathrm{s}$ for fat (obtained from $\nu=0.47$ ) suggests that slight-curvature of the otherwise-linear Hugoniot relationship for the adipose material exists at low particle velocities. Given the nature of the adipose material and the limited suitability of manganin pressure gauges in measuring shock at such low stress levels, detailed interrogation of the suggested curvature of the Hugoniot in the lower particle velocity region is not further practicable. Nevertheless, curvature at low particle velocity for otherwise linear Hugoniots has been witnessed elsewhere for polymers. ${ }^{16,35}$ The linear relationships established for Polyethylene, Polypropylene, and Polystyrene provide $\mathrm{c}_{0}$ (linear Hugoniot intercept) values of $2.34 \mathrm{~mm} / \mu \mathrm{s}, \quad 2.90 \mathrm{~mm} / \mu \mathrm{s}$, and $2.21 \mathrm{~mm} / \mu \mathrm{s}$, respectively. ${ }^{15}$ These values are significantly higher than the bulk sound speeds $\left(\mathrm{c}_{\mathrm{B}}\right)$ for each material; $2.05,2.18$, and $1.83 \mathrm{~mm} / \mu \mathrm{s}$. Taken together, the combination of experimental results; the trend in polymers to exhibit lower sound speeds than values obtained through a linear-fit intercept; and a calculated value of $\mathrm{c}_{0}$ at $\sim 1.45 \mathrm{~mm} / \mu$ s for fat (assuming 
$\nu=0.49$ ), further reinforce the suggestion that the bulk sound speed of the rendered porcine fat tested here should be lower than the linear-fit value of $\mathrm{c}_{0}=1.58 \mathrm{~mm} / \mu \mathrm{s}$.

The main mechanism proposed to explain curvature of the $U_{s}-u_{p}$ Hugoniot at lower particle velocities involves two stages: (1) primary reduction in the spaces between the polymeric chains, due to the existence of weak van der Waals forces, before; (2) secondary compression of the backbone carbon chain. Although this mechanism is arguably applicable to polymers in general, Carter et al. ${ }^{16}$ discussed the existence of phase changes within certain polymeric materials at low pressures and how these could also account for such observations. Further, other theories describing this behavior in polymers also exist, such as the elastic-plastic flow model, ${ }^{36}$ which predicts extreme curvature of the Hugoniot at low particle velocities. Consequently, the inclusion of the data-point corresponding to an impact velocity of $39 \mathrm{~m} / \mathrm{s}$, suggesting slight-curvature in the Hugoniot of the adipose material at low particle velocities, supports evidence that the material possesses structural similarity to simple polymers.

In terms of basic repeat structure, the polymer chain of polyethylene, which does not possess side group attachments, is somewhat similar to lard. Excluding the presence of glycerol within the triglyceride molecule, which is both a key structural component of fat and a functional group that will have significant effect of the response of the material to shock compression, the two materials both possess a long carbon chain without attachment-essentially a $\mathrm{CH}_{2}$ repeat. Lard exists as a semi-solid at room temperature due to the largely saturated nature of the fatty acid chains contained within it. Saturation of fatty materials may vary, however, and as discussed, ${ }^{12}$ the variance in percentage saturation is known to have an effect on material firmness.

Millett and Bourne ${ }^{15}$ studied the shock loading of polyethylene (no side group), polypropylene (methyl side group), and polystyrene (benzene side group). It was found that as the complexity, or size, of the side chain addition to the repeat unit increased, there was an increase in the shear strength of the material (i.e., its ability to resist compression under shock loading). Essentially, greater resistance to the compression that accompanies increases in stress was encountered with more complex polymer chain side groups. It has been postulated that there is a direct link between the key shock parameters $\mathrm{c}_{0}$ and $\mathrm{S}$ (the shock velocity at $\mathrm{u}_{\mathrm{p}}=0$ and the slope of the equation-of-state in the $\mathrm{U}_{\mathrm{s}}-\mathrm{u}_{\mathrm{p}}$ plane, respectively) and the physical material properties. Higher values of $\mathrm{c}_{0}$ have been linked to a greater resistance to compression, ${ }^{37}$ while lower values of $\mathrm{S}$ have been linked both to increased resistance to compression and enhanced material stiffness. ${ }^{38}$ As shown in Fig. 6, the value of $\mathrm{S}$ is significantly lower for gelatin than lard (1.77 and 2.47, respectively). This suggests that gelatin will show a greater resistance to $1 \mathrm{D}$ strain than the adipose material. ${ }^{38}$

In contrast with Shepherd et al., ${ }^{9}$ where it was shown that $20 \mathrm{wt} \%$ ballistic gelatin behaves hydrodynamically, i.e., it exhibits no significant shear strength, the adipose material investigated here appears to strengthen under dynamic loading. This behavior is reflected in an increase in the gradient of the experimental lard data above the included hydrody-

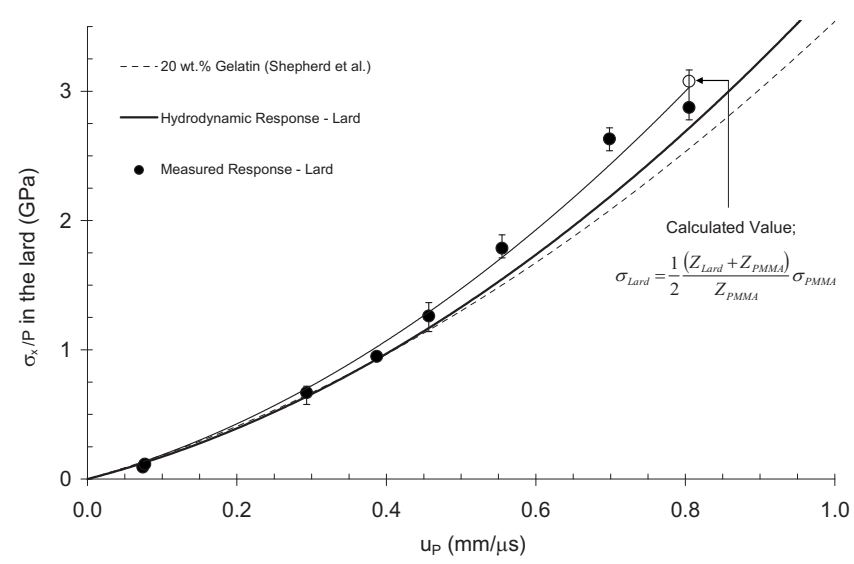

FIG. 7. P- $\mathrm{u}_{\mathrm{p}}$ Hugoniot of the food-grade lard and $20 \mathrm{wt} \%$ gelatin.

namic lines with increased impact stress in the $\mathrm{P}-\mathrm{u}_{\mathrm{p}}$ and $\mathrm{P}-\mathrm{v}$ Hugoniot relationships (Figs. 7 and 8, respectively). The P- $\mathrm{u}_{\mathrm{p}}$ Hugoniot shown in Fig. 7 also includes the hydrodynamic response curve for $20 \mathrm{wt} \%$ gelatin (experimentally found to be equivalent to the $\mathrm{P}-\mathrm{u}_{\mathrm{p}}$ Hugoniot ${ }^{9}$ ). This serves to highlight a key difference between material behaviors. Hydrodynamic curves are calculated according to Eq. (2). From Fig. 7 it is apparent that at $\mathrm{u}_{\mathrm{p}}=\sim 0.7 \mathrm{~mm} / \mu$ s a difference in pressure of ca. $0.5 \mathrm{GPa}$ would result between $20 \mathrm{wt} \%$ ballistic gelatin and the rendered fat. This suggests that there is a significant difference in the response of the two materials at elevated particle velocities. Furthermore, at very high shock pressures (beyond the scope of the experiments presented here) a substantial difference in response of the two materials is anticipated due to the divergent nature of the two curves.

$$
P=\rho_{0} U_{s} \mathrm{u}_{p} .
$$

The $\sigma_{\mathrm{x}} /$ pressure value for the datapoint corresponding to the largest stress and particle velocity in the P- $\mathrm{u}_{\mathrm{p}}$ and P-v Hugoniots presented in Figs. 7 and 8 was calculated from the rear-surface trace according to Eq. (1). As shown in both Hugoniot planes, there is some discrepancy between the front and (adjusted) rear-surface $\sigma_{x}$ /pressure for this datapoint. However, despite this discrepancy, in both cases measurable deviation from the hydrostatic response occurs; indicative of strengthening. Adoption of the rear-surface value for $\sigma_{\mathrm{x}}$ in determining the experimental best-fit was felt to be justified here for two reasons: (i) due to the good agreement with the deviation from the hydrostat apparent for the

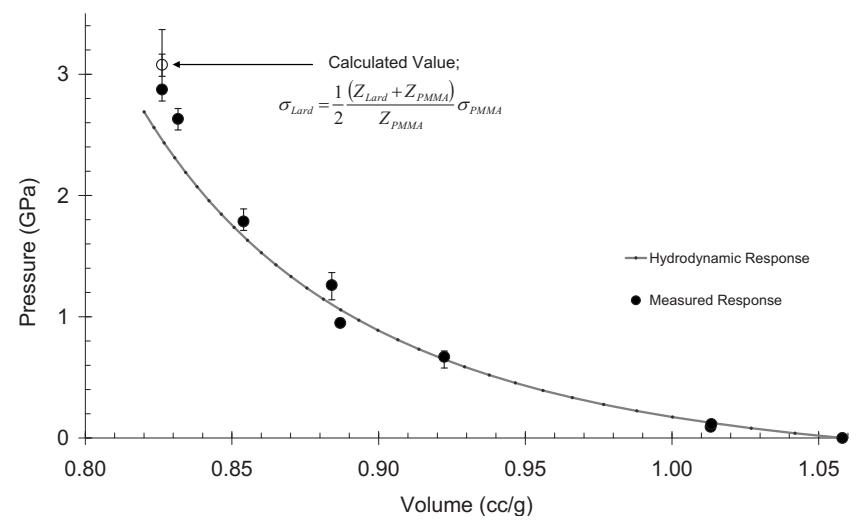

FIG. 8. P-v Hugoniot of the food-grade lard. 
TABLE II. Lateral gauge gradients established behind the shock.

\begin{tabular}{lllll}
\hline \hline $\begin{array}{l}\text { Impact velocity }(\mathrm{m} / \mathrm{s}) \\
\text { Gradient behind the }\end{array}$ & 346 & 405 & 682 & 804 \\
\begin{tabular}{l} 
shock $(\mathrm{GPa} / \mu \mathrm{s})$ \\
\hline
\end{tabular} & -0.01837 & -0.04996 & -0.05080 & -0.02097 \\
\hline
\end{tabular}

$758 \mathrm{~m} / \mathrm{s}$ datapoint from Table II in Figs. 7 and 8, and; (ii) due to anomalous features on the recorded front-gauge trace which made determination of a Hugoniot stress problematic.

The long-chain structure of lard/fat and the strengthening behavior of the material in the $\mathrm{P}-\mathrm{u}_{\mathrm{p}}$ plane under shock loading appear to be broadly similar to that of simple polymers. ${ }^{15,16,39}$ It therefore seems reasonable to suggest that this biological material has similar properties to its synthetic counterparts in the high stress/strain-rate regime.

It is generally accepted that the shear strength $(\tau)$ of a material governs its response under shock loading. The relationship between shear strength, the pressure $(\mathrm{P})$, and the longitudinal stress $\left(\sigma_{\mathrm{x}}\right)$ is given in Eq. (3).

$$
\begin{aligned}
& \sigma_{\mathrm{x}}=\mathrm{P}+\frac{4}{3} \tau \max , \\
& 2 \tau=\sigma_{\mathrm{x}}-\sigma_{\mathrm{y}} .
\end{aligned}
$$

Equation (4) relates longitudinal and lateral stresses generated within a material to the materials shear strength. Both stresses are known to vary with impact velocity. As such, knowledge of both $\sigma_{\mathrm{x}}$ and $\sigma_{\mathrm{y}}$ evolution within the rendered porcine fat for a range of impact conditions should allow characterization of its shear strength response to shock.

\section{B. Lateral response}

A total of four experiments were conducted to investigate the lateral stresses generated within the rendered porcine fat under shock loading conditions. Further, comparison has been made between the effects of the presence, or lack thereof, of an encapsulating Mylar ${ }^{\circledR}$ layer around the gauge element (but not ahead of the gauge) upon the response of the gauge to shock. Initially, two $10 \mathrm{~mm}$ thick copper flyer-plate experiments at impact velocities of 405 and $682 \mathrm{~m} / \mathrm{s}$ were conducted. Here, lateral gauges were encapsulated between two $50 \mu \mathrm{m}$ Mylar ${ }^{\circledR}$ layers before lard was cast around the gauge package. A further two experiments, in which no encapsulating Mylar ${ }^{\circledR}$ layer was present, were conducted at impact velocities of 346 and $804 \mathrm{~m} / \mathrm{s}$, also using $10 \mathrm{~mm}$ copper flyer-plates.

Lateral gauges are typically employed to investigate the development of lateral stresses in metals and polymers. ${ }^{24,40,41}$ Despite the nature of the food-grade lard, i.e., its semisolid state at room temperature, the techniques used in this work have allowed for successful measurement of a material response. Adopting a value of $\mathrm{c}_{0}=1.45 \mathrm{~mm} / \mu \mathrm{s},{ }^{33,34}$ and taking Poisson's ratio to be 0.47 , lateral response data for the adipose material has been presented in this work as calibrated stress-time plots, see Fig. 9. At impact velocities of 804 and $346 \mathrm{~m} / \mathrm{s}$ the gauge element was positioned $4 \mathrm{~mm}$ from the impact face of the target, while a distance of $6 \mathrm{~mm}$ was used during the 682 and $405 \mathrm{~m} / \mathrm{s}$ impacts. Such placement corresponds to distances of $6 \mathrm{~mm}$ and $4 \mathrm{~mm}$, respec-

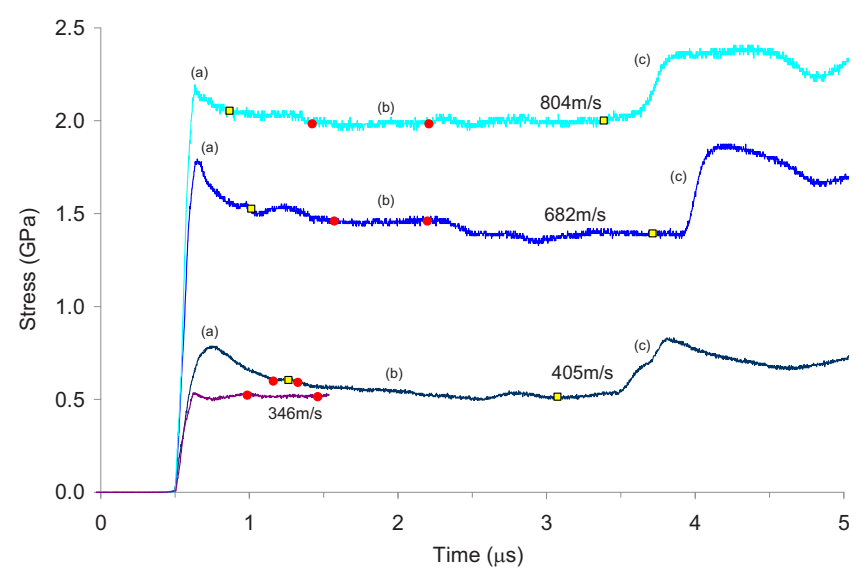

FIG. 9. (Color online) Lateral shock-response of lard.

tively, from the rear of the $10 \mathrm{~mm}$ target ring in all but the $346 \mathrm{~m} / \mathrm{s}$ shot. In the case of the $346 \mathrm{~m} / \mathrm{s}$ impact, a smaller target ring thickness of $6 \mathrm{~mm}$ meant that the gauge element sat only $2 \mathrm{~mm}$ from the rear of the target when placed at a distance of $4 \mathrm{~mm}$ from the impact face. This arrangement produced unfavorable noise within the $346 \mathrm{~m} / \mathrm{s}$ trace from $\mathrm{t}$ $=$ ca.1.5 $\mu$ s onwards, most likely due to re-loading upon reflection of the shock from the rear of the target. As a result, $346 \mathrm{~m} / \mathrm{s}$ data for $\mathrm{t}>1.56 \mu \mathrm{s}$ after impact has been omitted from the lateral gauge traces in Fig. 9. The square markers on gauge traces in Fig. 9 correspond to the range over which gradients behind the shock have been established. Circular markers correspond to the range over which average stress values have been measured in order to give an indication of the shear strength of the material over that time.

There are a number of points to note from the lateral response data for the adipose material (see Fig. 9). First, as impact velocity increases, so do both the initial gradient and amplitude of the gauge response corresponding to shock arrival. Such behavior is indicative of (i) an increase in shock velocity, and, (ii) the subsequent increase in pressure generated within the target material as a result of greater shock velocity. However, it should be noted that such a combined response is generally expected from the relative change in impact conditions.

Initial overshoots (a) can be seen to occur upon shock arrival at impact velocities of 405, 682, and $804 \mathrm{~m} / \mathrm{s}$ in Fig. 9; however, this artifact appears to be significantly enhanced in targets where an encapsulating layer was present, i.e., at impact velocities of 405 and $682 \mathrm{~m} / \mathrm{s}$. Notably, an overshoot is not clearly discernible at $346 \mathrm{~m} / \mathrm{s}$, which lacked a Mylar ${ }^{\circledR}$ encapsulating layer. Similar overshoots to those seen in the lateral response of the adipose material have been observed in longitudinal gauge traces (Fig. 5). This behavior in longitudinal gauges, however, has been attributed to an electrical capacitance effect between the gauge and the surface of the target material. $^{29}$

One explanation proposed in the literature for such overshoots in lateral gauge response is based on the concept of differing shock velocities in the target/matrix (generally metals and polymers) and the encapsulation layer, leading to the formation of a Mach-stem. Hydrocode simulations undertaken by Winter and Harris ${ }^{42}$ indicated that if the shock in 
the matrix runs ahead of the shock in the encapsulation, the pressure, and hence the determinant stress, will be initially characterized by an overshoot with a subsequent decay in magnitude behind. Conversely, a continuous rise in pressure/ stress with time would be apparent when the shock in the matrix lags the shock in the encapsulation.

Slight negative gradients are apparent behind the shock in the adipose material [see (b) in Fig. 9]. However, it should be stressed that the relatively noisy nature of the $\sigma_{\mathrm{y}}$ stress response behind the shock-attributed to the nature of the adipose material under test makes determination of such gradients highly subjective. Nevertheless, the calculated magnitudes of the gradients taken between the two square markers on gauge traces and the circular markers on the $346 \mathrm{~m} / \mathrm{s}$ trace are presented in Table II. In addition to the observed reduction in the overshoot in stress witnessed upon shock arrival, the gradients in Table II appear to suggest that the lack of encapsulating Mylar ${ }^{\circledR}$ also reduces the magnitude of the negative gradient established behind the shock. This appears to be the case for both maximum and minimum impact velocities tested here. At first glance, experimental results seem to suggest that the overshoot witnessed upon shock arrival is, as proposed by Winter and Harris, ${ }^{42}$ an artifact caused by Mach-stem formation between the matrix and the encapsulating Mylar ${ }^{\circledR}$ layer/gauge packaging. However, the combination of; (i) rapid rise times witnessed for longitudinal gauges $(<125 \mathrm{~ns})$, suggesting a close match in impedance between the gauge packaging and the epoxy resin used in target construction and (ii) the form of the Hugoniot relationships of epoxy resin and PMMA within the literature $\left[\mathrm{U}_{\mathrm{s}}\right.$ $=2.65+1.55 \mathrm{u}_{\mathrm{p}}$ (Ref. 43) and $\mathrm{U}_{\mathrm{s}}=2.59+1.52 \mathrm{u}_{\mathrm{p}},{ }^{16}$ respectively] suggests that the velocity of the shock in the gauge encapsulation, modeled as either PMMA or epoxy resin, will be greater than the velocity of the shock in the matrix (lard) at particle velocities $<1.16 \mathrm{~mm} / \mu \mathrm{m}$. Lateral experiments conducted here correspond to particle velocities of less than $1 \mathrm{~mm} / \mu \mathrm{s}$. Consequently, the overshoots witnessed in stress upon shock arrival are unlikely to be the result of a Machstem between the matrix and the gauge package in this case. Evidence of a slight overshoot at the higher impact velocity of $804 \mathrm{~m} / \mathrm{s}$, despite exclusion of an encapsulating Mylar ${ }^{\text {B }}$ layer, suggests that the overshoot is part of an inherent response of lateral gauges to the onset of shock. However, it is reasonable to suggest that this artifact may only be observed at significant levels at higher impact velocities, e.g., $804 \mathrm{~m} / \mathrm{s}$. At point (c) in Fig. 9, reloading occurs, most likely as the result of a reflection of the shock from the PMMA backing material, due to its higher density and shock impedance.

For a given material, if longitudinal stress remains constant while lateral stress decreases, Eq. (4) suggests that the shear strength will increase. The adipose material has been observed to exhibit both constant longitudinal stress [see point (c) in Fig. 5] and indications of a possible slight negative gradient behind the shock in lateral investigations. This therefore suggests the possibility of an increase in shear strength within the material under shock loading conditions. However, the magnitudes of the gradients established behind the shock and lack of any significant change in gradient for a range of impact velocities implies that any increase in shear strength is; (a) minimal and (b) independent of the shock velocity, i.e., an increased shock velocity within the adipose material may not result in an increase in the rate of change in shear strength. Furthermore, the relatively small magnitude of the gradients recorded behind the shock may suggest that such measurements lie close to the limit of experimental noise. Appleby-Thomas et al. ${ }^{44}$ previously presented a limited part of the data set shown in Fig. 9 as raw voltage data. Observations from this previous data set showed (i) a more significant rate of change of increase in shear strength for the adipose material and (ii) a pressure-dependant rate of change in shear strength. Such observations contradict those presented for the material here. However, it is reasonable to suggest that the raw voltage data for the adipose material may not completely correspond to lateral stress interpretations. Despite the listed differences between stress-time and voltage-time lateral data, and the fact that it is hard to deconvolute experimental data from noise, both sets of results are in agreement that a (small) change in shear strength appears to be observed for the rendered porcine fat under shock loading. This result correlates well with lateral response data for polymers observed elsewhere. ${ }^{39,25}$

The dynamic shear strength response of the polymeric material, Sylgard, has been investigated. ${ }^{41}$ Notably, a similar experimental approach was taken i.e., the casting of lateral gauges within the target material. Sylgard was shown to possess an increase in lateral stress with time behind the shock-in likeness with the apparent response of the adipose material here. In both cases, this has been shown to result in an increase in shear strength with time; however, the data presented for Sylgard does not clearly indicate the possible existence of a pressure-dependent rate of change in shear strength with time i.e., steepening of the negative lateral stress gradient behind the shock. It is postulated that, while the rendered fat strengthens at a rate that is independent of the pressures investigated here, shown via a mechanism of negligible change in lateral stress gradient behind the shock, Sylgard would exhibit a pressure-dependent response due to cross-linkage between its polymeric chains. This suggestion is backed by the pressure-dependent rate of change in shear strength response of resin transfer molding (RTM) 6, also exhibiting cross-linkage, provided by Appleby-Thomas et $a .^{25}$

The increase in deviation of the Hugoniot stress of the adipose material above the hydrodynamic curve in the $\mathrm{P}-\mathrm{u}_{\mathrm{p}}$ and P-v planes is suggestive of the fact that the material exhibits increased strengthening with pressure. However, this behavior is only significant at higher impact velocities, e.g., 758 and $882 \mathrm{~m} / \mathrm{s}$. As discussed, the adipose material has been shown to exhibit a minimal rate of change in lateral stress, and hence shear strength, with increased pressure over the range of impact conditions examined here. Given this, it seems reasonable to suggest that the homogenous rendered fat might exhibit an increase in negative gradient, corresponding to an increased rate of change in lateral stress, at higher pressures than those examined here. Absence of such a response at elevated pressures would suggest saturation of any strengthening mechanism at shock pressures of the order of those examined here. It has also been shown that, while 
the rate of change in shear strength behind the shock is a time-dependent response of the adipose material, the significant increase in constant longitudinal stresses above the hydrodynamic response appears to be a near instantaneous response of the material to the onset of shock.

\section{CONCLUSIONS}

Flyer-plate impact experiments have successfully allowed for the formation of an equation-of-state for a rendered porcine fat, with the linear form $\mathrm{U}_{\mathrm{s}}=1.58+2.47 \mathrm{u}_{\mathrm{p}}$ given a density of $0.9451 \mathrm{~g} / \mathrm{cm}^{3}$.

This work has shown that a ca. approximately $99.8 \%$ fat material-highly analogous to human body fat-exhibits a strengthening characteristic when subjected to dynamic loading within the high strain-rate range of investigations. Both the equation-of-state and the strengthening characteristic of the material under shock loading provide contrasting behavior to that of water and $20 \mathrm{wt} \%$ ballistic gelatin.

Although an excellent medium for displaying projectile behavior under impact, by mechanism of transparency, ballistic gelatin cannot be fully representative of fatty tissues, skeletal muscle, or the varying types of smooth muscle which make up the hollow organs, glands, and skin. In general, it is not reasonable to assume that these tissue types possess a lack of significant strength, as shown for ballistic gelatin or water under shock loading.

Investigations into the lateral response of the adipose material have highlighted several key features, namely; (1) the adipose material appears to display a very small increase in shear strength behind the shock, albeit subject to a somewhat subjective choice of gradient measurement sampling positions; (2) the rate of change in the apparent increase in shear strength in the lard appears to be independent of impact stress, and; (3) the initial overshoot in stress witnessed in lateral gauge traces upon shock arrival is unlikely to be the result of Mach-stem formation between the encapsulation/ gauge package and matrix (lard).

The tested adipose material in this work provides an initial data set and characteristic behavior of a material that, to the best of the authors' knowledge, has previously remained un-tested under such loading regimes. The behavior of the material has been investigated for a range of impact pressures corresponding to the limitations of the adopted experimental technique i.e., the single-stage gas gun employed during experiments. As such, future work may seek to highlight (i) the behavior of the material at higher pressures than those investigated in this paper and (ii) possible differences in the dynamic properties of various classes/grades of fat.

\section{ACKNOWLEDGMENTS}

The authors would like to acknowledge the invaluable technical assistance provided by $\mathrm{Mr}$ Andy Roberts of the Dynamic Response Group, Cranfield University. One of the authors, James Wilgeroth, who is a Ph.D. student at Cranfield University, is indebted to Cranfield Defense and Security for the funding that made this work possible.

${ }^{1}$ J. H. McElhaney, J. Appl. Physiol. 21, 4 (1966).
${ }^{2}$ H. Saraf, K. T. Ramesh, A. M. Lennon, A. C. Merkle, and J. C. Roberts, J. Biomech. 40, 1960 (2007).

${ }^{3}$ M. M. Al-Mousawi, S. R. Reid, and W. F. Deans, Proc. Inst. Mech. Eng. 211, 4 (1997).

${ }^{4}$ S. T. Marais, R. B. Tait, T. J. Cloete, and G. N. Nurick, Latin American Journal of Solids and Structures 1, 319 (2004).

${ }^{5}$ B. Song, W. Chen, Y. Ge, and T. Weerasooriya, J. Biomech. 40, 2999 (2007).

${ }^{6}$ O. A. Shergold, N. A. Fleck, and D. Radford, Int. J. Impact Eng. 32, 1384 (2006).

${ }^{7}$ C. Van Sligtenhorst, D. S. Cronin, and G. Wayne Brodland, J. Biomech. 39, 10 (2006).

${ }^{8}$ C. P. Salisbury and D. S. Cronin, Exp. Mech. 49, 829 (2009).

${ }^{9}$ C. J. Shepherd, G. J. Appleby-Thomas, P. J. Hazell, and D. F. Allsop, AIP Conf. Proc. 1195, 1399 (2009).

${ }^{10}$ K. Nagayama, Y. Mori, Y. Motegi, and M. Nakahara, AIP Conf. Proc. 845, II (2006).

${ }^{11}$ K. Nagayama, Y. Mori, Y. Motegi, and M. Nakahara, Shock Waves 15, 267 (2006).

${ }^{12}$ T. Nishioka and M. Irie, Meat Sci. 70, 399 (2005).

${ }^{13}$ B. R. Mackenna and R. Callander, Illustrated Physiology, 5th ed. (Longman Group HK Limited, Edinburgh, 1997), p. 266.

${ }^{14}$ R. R. Seeley, T. D. Stephen, and P. Tate, Anatomy and Physiology (BurrRich, Boston, 1996).

${ }^{15}$ J. C. F. Millett and N. K. Bourne, J. Phys. D 37, 20 (2004).

${ }^{16}$ W. J. Carter, S. P. Marsh, and R. G. McQueen, Los Alamos National Laboratory Report No. LA-13006-MS, 1995.

${ }^{17}$ F. M. White, Fluid Mechanics, 3rd ed. (McGraw-Hill, New York, 1994).

${ }^{18}$ G. J. Appleby-Thomas, P. J. Hazell, C. Stennett, G. Cooper, K. Helaar, and A. M. Diederen, J. Appl. Phys. 105, 064916 (2009).

${ }^{19}$ N. K. Bourne and J. C. F. Millett, Proc. R. Soc., Math. Physic. Eng. Sci. 459, 2031 (2003).

${ }^{20}$ N. K. Bourne, Meas. Sci. Technol. 14, 273 (2003).

${ }^{21}$ V. E. Keilin and V. K. Shleifman, J. Appl. Phys. 51, 7 (1980).

${ }^{22}$ M. A. Meyers, Dynamic Behavior of Materials (John Wiley \& Sons, New York, 1994).

${ }^{23}$ G. J. Appleby-Thomas, P. J. Hazell, J. Millett, and N. K. Bourne, AIP Conf. Proc. 1195, 533 (2009).

${ }^{24}$ J. C. F. Millett, G. Whiteman, and N. K. Bourne, J. Appl. Phys. 105, 033515 (2009).

${ }^{25}$ G. J. Appleby-Thomas, P. J. Hazell, and C. Stennett, J. Mater. Sci. 44, 6187 (2009).

${ }^{26}$ Z. Rosenberg and Y. Partom, J. Appl. Phys. 58, 8 (1985).

${ }^{27}$ Z. Rosenberg and N. S. Brar, J. Appl. Phys. 77, 4 (1995).

${ }^{28}$ J. C. F. Millett, N. K. Bourne, and Z. Rosenberg, J. Phys. D 29, 2466 (1996).

${ }^{29}$ N. K. Bourne and Z. Rosenberg, Meas. Sci. Technol. 8, 570 (1997).

${ }^{30}$ A. Delalleau, G. Josse, J. Lagarde, H. Zahouani, and J. Bergheau, J. Biomech. 39, 9 (2006).

${ }^{31}$ J. J. Elsner and A. Gefen, J. Biomech. 41, 3322 (2008).

${ }^{32}$ J. V. Soulis, G. D. Giannoglou, Y. S. Chatzizisis, K. V. Seralidou, G. E. Parcharidis, and G. E. Louridas, Med. Eng. Phys. 30, 9 (2008).

${ }^{33}$ C. Li, N. Duric, P. Littrup, and L. Huang, Ultrasound Med. Biol. 35, 10 (2009).

${ }^{34}$ H. Shin, R. Prager, H. Gomersall, N. Kingsbury, G. Treece, and A. Gee, Ultrasonics 50, 716 (2010).

${ }^{35}$ G. J. Appleby-Thomas, P. J. Hazell, C. Stennett, and G. Cooper, 9th International Conference on the Mechanical and Physical Behaviour of Materials under Dynamic Loading, DYMAT 2009, 7-11 September 2009, Brussels, Belgium, Vol. 2, p. 1081.

${ }^{36}$ D. N. Schmidt and M. W. Evans, Nature (London) 206, 1348 (1965).

${ }^{37}$ J. C. F. Millett, N. K. Bourne, and J. Akhavan, J. Appl. Phys. 95, 9 (2004).

${ }^{38}$ L. Davison and R. A. Graham, Phys. Rep. 55, 255 (1979).

${ }^{39}$ N. K. Bourne, J. C. F. Millett, and S. G. Goveas, J. Phys. D 40, 5714 (2007).

${ }^{40}$ J. C. F. Millett, G. T. Gray III, and N. K. Bourne, J. Appl. Phys. 101, 033520 (2007). 
${ }^{41}$ J. C. F. Millett, G. Whiteman, S. M. Stirk, and N. K. Bourne, Society for Experimental Mechanics-SEM Annual Conference and Exposition on Experimental and Applied Mechanics, 1-4 June, 2009, Albuquerque, NM (Curran Associates, Inc., Red Hook, NY, 2009), Vol. 1, p. 498.
${ }^{42}$ R. E. Winter and E. J. Harris, J. Phys. D 41, 3 (2008).

${ }^{43}$ P. J. Hazell, C. Stennett, and G. Cooper, Polym. Compos. 29, 1106 (2008).

${ }^{44}$ G. J. Appleby-Thomas, P. J. Hazell, J. M. Wilgeroth, and D. C. Wood, J. Appl. Phys. 108, 033524 (2010). 